\title{
Resistência e tolerância a impacto transversal de baixa energia de um laminado híbrido metal/fibra
}

\author{
GUALBERTO, A.R.M.; GATT, M.C.A.; TARPANI, J.R. \\ Departamento de Engenharia de Materiais - Escola de Engenharia de São Carlos - Aeronáutica e \\ Automobilística - EESC -USP - Avenida Trabalhador São-Carlense, 400 - CEP 13566-590, \\ São Carlos, SP, Brasil \\ e-mails: gualberto@sc.usp.br, mcgatti@sc.usp.br, jrpan@sc.usp.br
}

\section{RESUMO}

A energia absorvida no impacto transversal do laminado híbrido metal/fibra Glare ${ }^{\circledR}$ foi determinada por três diferentes métodos. O primeiro método utiliza um sofisticado aparato Laser-Doppler que registra a aceleração e a desaceleração do impactador ao longo do evento de choque mecânico por queda-de-peso, enquanto que o segundo se baseia apenas nos dados de carga de impacto contra o tempo de contato do impactador com o espécime. Já o terceiro método considera somente as velocidades do impactador pré- e pós-impacto. Concluiu-se que as duas primeiras metodologias geram resultados bastante similares entre si, com o material em geral absorvendo cerca de $70 \%$ da energia disponibilizada no impacto, enquanto que a terceira abordagem apresentou resultados excessivamente não-conservadores. As propriedades residuais em flexão dos laminados previamente danificados por impacto demonstraram que o módulo de elasticidade é o parâmetro mais confiável para a monitoração do grau de integridade estrutural do compósito híbrido.

Palavras chaves: danos por impacto de baixa energia, laminado metal/fibra, material compósito.

\section{Low-Energy transverse impact resistance and tolerance of hybrid fiber/metal laminate}

\begin{abstract}
The absorbed energy during the low-velocity transversal impact of hybrid metal/fiber Glare ${ }^{\mathrm{TM}}$ laminate was determined by three different analytical methods. The first method employs a sophisticated Laser-Doppler apparatus that registers the acceleration and deceleration of the impact tup along the dropweight test, whereas the second one is based only on the impact load-time history. The third method relies solely on the pre- and post-impact velocity of the striker. It has been concluded that the first two methodologies produce very similar results, with the material generally absorbing approximately $70 \%$ of the available energy, while the third methodology generated unduly non-conservative results. Residual flexural properties of previously impact damaged laminate specimens showed that the modulus of elasticity is the most valuable parameter for structural integrity monitoring of the hybrid composite.
\end{abstract}

Keywords: Composite material, fiber/metal laminate, low-energy impact damage.

\section{INTRODUÇÃO}

\subsection{Laminados metal/fibra}

A classe dos laminados híbridos metal/fibra (LMF) foi concebida na década de 50 na Universidade Delft (Holanda), em parceria com a empresa aeronáutica holandesa Fokker [1]. Tipicamente, os LMFs são compostos por camadas de uma liga metálica (e.g., aço, ligas-Al, -Mg ou -Ti) intercaladas com camadas de fibras resistentes (e.g., vidro, aramida, carbono ou polipropileno) pré-impregnadas com resina (termorrígida ou termoplástica), conforme ilustra a Figura 1. 


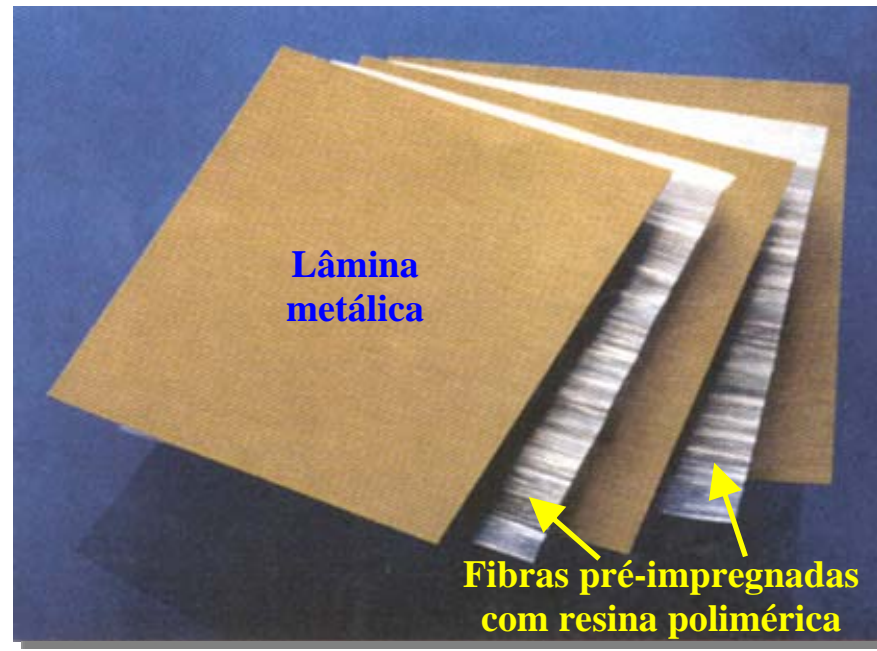

Figura 1: Arranjo típico de fases em um laminado híbrido metal/fibra.

O Glare ${ }^{\circledR}$ (Glass Reinforced Fiber/Metal Laminate), constituído por lâminas de liga-Al interdispersas com mantas de fibras fortalecedoras de vidro imersas em resina epóxi, é atualmente o laminado híbrido de maior potencial aplicativo na indústria aeronáutica [1,2].

Dada a arquitetura construtiva do Glare, que alia alta resistência à propagação de trincas de fadiga a uma reduzida densidade do laminado, é possível alcançarem-se reduções da ordem de $30 \%$ do peso estrutural em de veículos aéreos [1] , proporcionando um significativo acréscimo na chamada carga paga (pay load) e/ou do número de passageiros transportados, fatores que constituem a força motriz da indústria aeronáutica comercial. Como exemplo, mais de $500 \mathrm{~m}^{2}$ deste material estão sendo empregados em cada nova aeronave super-jumbo Airbus A380 (Figura 2), garantindo desta forma uma economia de peso de cerca de 1 ton.

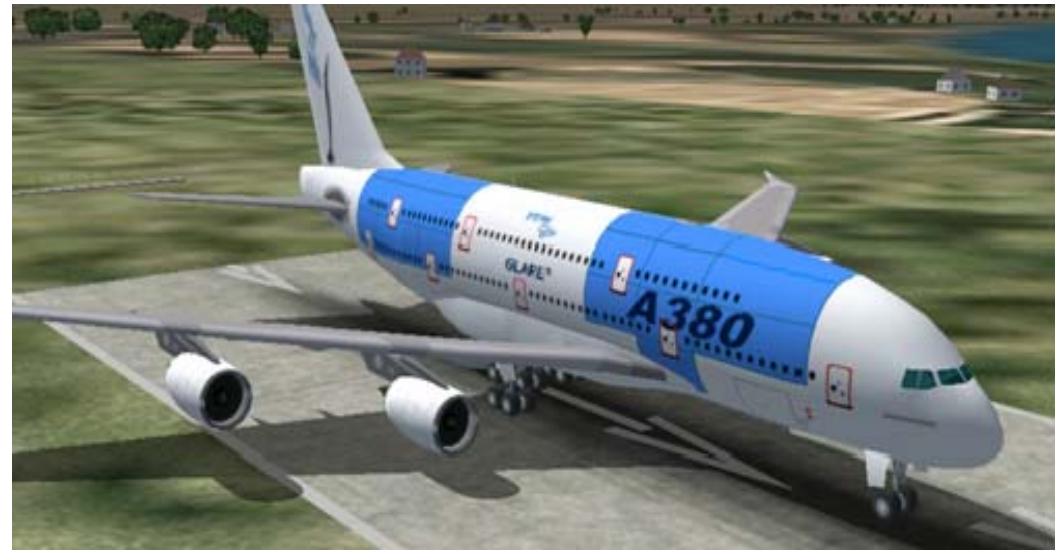

Figura 2: Fuselagem superior da aeronave Ai rbus A380, confeccionada com Glare.

A grande atratividade exercida pelo LMF-Glare à indústria aeronáutica incitou forte interesse também por parte da indústria automobilística (e.g., Ford Motor Co.), que pretende utilizar esta classe de materiais na carenagem de seus veículos de passeio. Porém, desta feita, polímeros termoplásticos (e.g., polipropileno, nylon e ABS), ao invés dos termorrígidos (e.g., epóxi, bismaleimida), são preferidos em vista da alta produtividade requerida pela indústria automotiva, assim como devido às múltiplas operações de conformação mecânica tipicamente empregadas na fabricação destas estruturas de veículos automotores [్5]. Redução de peso (economia de combustível e/ou maior autonomia) e um bom desempenho sob impacto (crashworthiness) são aspectos claramente desejáveis também nestas aplicações.

Visto que, diferentemente do setor aeronáutico, no setor automotivo há freqüentes limitações quanto à disponibilidade de equipamentos laboratoriais para a caracterização mecânica de materiais estruturais, o desenvolvimento de metodologias mais rápidas e baratas para a determinação da resistência e tolerância a danos dos LMFs pode acelerar significativamente a difusão desta classe de materiais também neste ramo mais popular da indústria da mobilidade. 


\subsection{Danos por impacto}

Uma grande quantidade de trabalhos já foi publicada na literatura a respeito dos efeitos dos impactos de média e alta energias nos LMFs [ $\underline{6}-\underline{11}]$.

Entretanto, pesquisas sobre impactos leves em LMFs, com energia abaixo dos 10 Joules, os quais são comuns tanto no ambiente aeronáutico quanto no automotivo, em especial durante as operações de inspeção, reparo e manutenção destes veículos e seus componentes, são raras na literatura científica [12]. Embora a justificativa para esta escassez de resultados possa ser a de que a resistência mecânica do material híbrido seja pouco afetada por impactos com energia abaixo deste valor [11], pode-se, por outro lado, argüir que o efeito destes danos no módulo de elasticidade, ou seja, na rigidez do laminado é significativo, com o conseqüente comprometimento da integridade residual da estrutura avaliada. Além disso, há de se considerar a possibilidade da repetição destes choques mecânicos de baixa energia, configurando a chamada fadiga por impacto, que ocorre tipicamente em algumas posições específicas de uma aeronave (e.g., bordos de ataque, fuselagem, soalhos, revestimentos internos). Num contexto propício, estes múltiplos impactos podem culminar em danos de grande monta e na substancial degradação das propriedades mecânicas do material [13-15].

Ademais, analogamente ao verificado nas estruturas aeronáuticas convencionais fabricadas em ligas monolíticas de alumínio [16], a subseqüente aplicação de cargas cíclicas de fadiga ao componente impactado pode ser suficiente para o crescimento dos danos previamente introduzidos por impacto. Neste sentido, foi verificada [17] a sensibilidade das delaminações à fadiga pós-impacto em laminados compósitos, com a resultante perda progressiva de propriedades mecânicas fundamentais, em especial da resistência à compressão no plano, ou seja, à flambagem [18]. Preconiza-se, portanto, que tais efeitos possam vir a ser observados, em maior ou menor extensão, com uma maior ou menor freqüência, também nas estruturas de veículos automotores a serem confeccionados em compósitos laminares.

Outra questão importante relacionada aos impactos de baixa energia refere-se ao conceito de "danos de difícil deteç̧ão visual” (BVID - Barely Visible Impact Damage, [19]). Segundo este conceito, danos causados por impacto abaixo de uma determinada energia limite, estabelecida em termos da detectabilidade do dano correspondente (e.g., uma depressão com $0,3 \mathrm{~mm}$ de profundidade, ou então uma indentação cuja identificação visual é possível a uma distância da ordem de poucos metros), embora passíveis de não serem detectados em uma inspeção visual rotineira (walk around), podem reduzir significativamente a resistência

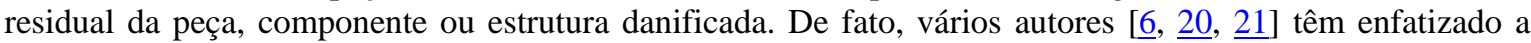
necessidade da caracterização dos danos devidos aos impactos nos laminados metal/fibra, independente do nível de energia aplicado, visto que estes degradam substancialmente as propriedades mecânicas residuais desta classe de materiais estruturais.

\subsection{Metodologias experimentais e analíticas para a determinação da resistência a impactos transversais}

\subsubsection{Introdução}

Um aparato experimental básico de impacto sob queda-de-peso (drop-weight) consiste essencialmente de um impactador com uma determinada massa $(m)$, sujeito à queda livre, ao qual é acoplada uma célula de carga que proverá pontos de dados de carga $(F)$ contra o tempo de contato $(t)$ entre o impactador e o alvo (no caso, um LMF). Os dados assim obtidos são amplificados e enviados a um computador para processamento e análise dos resultados.

\subsubsection{Método Laser-Doppler (LD)}

Uma sofisticação do sistema acima descrito consiste na incorporação de um dispositivo LaserDoppler, o qual emite um feixe de laser que, ao ser refletido no impactador, possibilita o registro contínuo da sua velocidade $(v)$ contra o tempo $(t)$ durante todo o evento do choque mecânico. Por intermédio de um diagrama $v$-t (Figura 3), é possível, via procedimento descrito na sequêencia do texto, a obtenção do correspondente diagrama de deslocamento do impactador (s) em função do tempo de impacto (Figura 4). Finalmente, a conjunção dos dados de carga vs. deslocamento $(F-s)$ permite, por meio de integração numérica, a estimativa da energia absorvida $\left(\mathrm{E}_{a}\right)$ pelo material-alvo. Isto é matematicamente estabelecido pela Eq.1: 


$$
E=\int F(s) d s
$$

onde:

$E_{a}$ : energia absorvida pelo espécime;

$F(s)$ : força aplicada em função do deslocamento experimentado pelo corpo-de-prova (cdp).

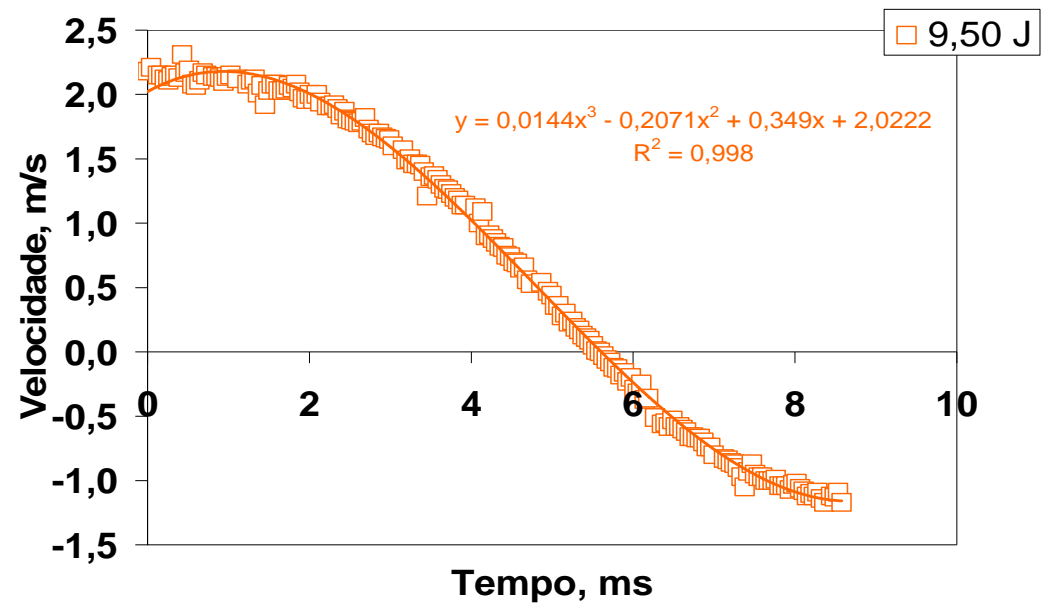

Figura 3: Velocidade do impactador em função do tempo de contato entre o projétil e o alvo para uma energia de impacto de $9,50 \mathrm{~J}$.

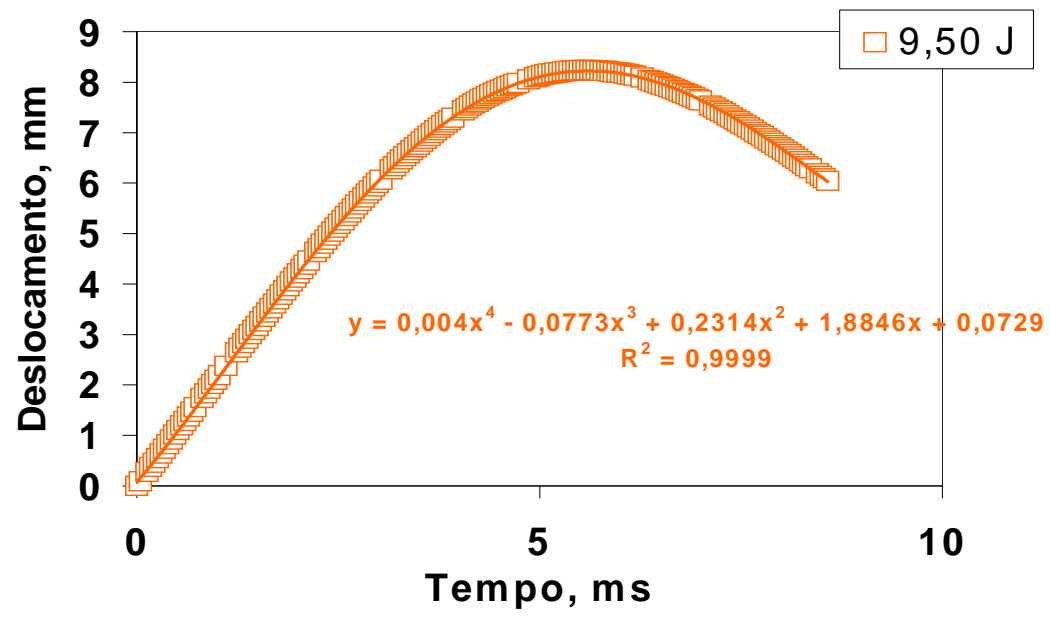

Figura 4: Deslocamento do impactador em função do tempo de impacto para uma energia total disponibilizada de 9,50 J.

\subsubsection{Método da célula de carga (CC)}

Este método de integração dispensa o uso de dispositivos sofisticados, requerendo apenas a história de carregamento na forma de pontos de dados $F$-t, os quais são supridos pela célula de carga acoplada ao impactador. O método CC permite obterem-se simultaneamente ambas as energias elástica (ou seja, recuperável) e consumida ou absorvida pelo espécime (ou seja, não-recuperável, que é essencialmente despendida em processos de danos e na deformação plástica do laminado híbrido metal-fibra) [7, 8, 22]. Por intermédio da Eq. 2 a velocidade pode ser determinada em função do tempo de impacto, enquanto que a Eq. 
3 permite a determinação da energia absorvida pelo espécime em função do tempo de contato entre projétil (impactador) e alvo (LMF). A massa ( $m$ ) é uma constante, assim como é a velocidade de impacto $\left(v_{i}\right)$ para uma dada altura de liberação do impactador, sendo esta última variável já conhecida antes do início do experimento. De fato, a famosa expressão de energia potencial: energia de impacto $=$ massa projétil * aceleração gravitacional * altura de liberação do projétil, é empregada na determinação da variável "altura de queda do peso”. Note-se que a Eq. 4 já relaciona diretamente a velocidade de impacto à energia contida no projétil com massa $m$ em um evento de impacto sob condições de queda livre.

$$
\begin{aligned}
& v(t)=v_{i}+\frac{1}{m} \int F d t \\
& E(t)=\frac{m \cdot v_{i}^{2}}{2}-\frac{m(v(t))^{2}}{2} \\
& v_{i}=\sqrt{\frac{2 \cdot E_{i}}{m}}
\end{aligned}
$$

onde:

$v(t)$ : velocidade instantânea do impactador;

$v_{i}$ : velocidade do impactador no limiar do choque com o alvo;

m: massa do impactador;

$F(t)$ : força instantânea aplicada ao espécime;

$E(t)$ : energia (J) transferida ao espécime no tempo $t(\mathrm{~s})$.

\subsubsection{Método do rebote (MR)}

Essencialmente, o procedimento consiste em calcular-se primeiramente a energia cinética do impactador no instante imediatamente anterior ao impacto (Eq. 4), e, em seguida, calcular-se a energia que o projétil adquire imediatamente após o impacto com o cdp (alvo), empregando-se a Eq. 5. A velocidade do impactador ao abandonar o material-alvo é denominada velocidade de rebote.

$$
E_{r}=\frac{m \cdot v_{r}^{2}}{2}
$$

onde:

$E_{r}$ : energia de rebote;

$v_{r}$ : velocidade de rebote.

Através da diferença entre as energias calculadas, respectivamente, pelas Eq.4 e Eq.5, a energia absorvida durante o evento do impacto pode ser estimada (Eq.6):

$$
E_{a}=E_{i}-E_{r}
$$

onde:

$E_{a}$ : energia absorvida (consumida) pelo espécime. 
O LMF-Glare-5 2/1 ${ }^{\circledR}$ é o resultado de um esforço focado na obtenção de um laminado híbrido otimizado para suportar cargas de impacto, característica esta provida principalmente pela fase metálica, porém sem comprometer significativamente sua resistência à propagação de trincas por fadiga, qualidade esta proporcionada essencialmente pelo reforço fibroso. O Glare-5 consiste de duas lâminas externas de liga de alumínio 2024-T3 com alta resistência mecânica e 0,5 mm de espessura cada, as quais ensanduicham 4 camadas de fibras unidirecionais impregnadas com resina epóxi e justapostas alternadamente segundo uma simetria central (i.e., $0^{\circ} / 90^{\circ} / 90^{\circ} / 0^{\circ}$ ), conforme esquema mostrado na Figura 5. Obtém-se, assim, um LMF com espessura de $1,6 \mathrm{~mm}$.

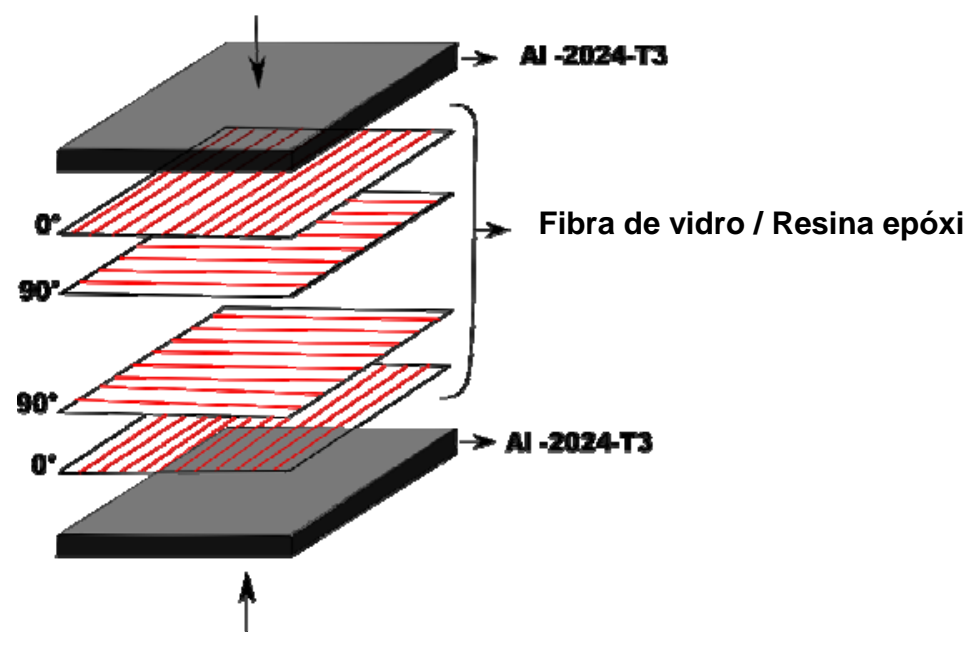

Figura 5: Laminado Glare-5 exibindo distribuição balanceada de fibras fortalecedoras de vidro, com iguais quantidades dispostas nas direções $0^{\circ} / 90^{\circ}$.

Corpos de prova (cdps) não normatizados, do tipo-tablete retangular, com espessura integral e dimensões no plano de $\left(27,5\right.$ x 65) $\mathrm{mm}^{2}$ foram extraídos de placas de Glare-5 confeccionadas industrialmente, empregando-se no corte serras mecânicas de precisão, em operação realizada pela Embraer S/A.

Merece ser destacado que MCkowns [23] considera válidos os ensaios mecânicos de impacto transversal realizados em cdps com pequenas dimensões empregados na simulação de estruturas e componentes mais robustos, desde que o dano impingido ao espécime se restrinja a uma porção significativamente pequena do tamanho do cdp. Esta restrição visa garantir que o modo de fratura dos LMFs não seja alterado com o acréscimo da escala do cdp (princípio da independência quanto ao tamanho do corpo-de-prova), sendo esta condição especialmente obedecida para os impactos mais leves, ou seja, os de baixa energia tais como aqueles avaliados no presente estudo.

\section{EXPERIMENTAL E ANALÍTICO}

\subsection{Ensaios mecânicos}

Neste trabalho foram empregados dois tipos de ensaios mecânicos de modo a caracterizar, respectivamente, a resistência e a tolerância a danos por impacto de baixa energia do LMF Glare-5:

- $\quad$ Ensaio de queda livre de peso (drop-weight test);

- $\quad$ Ensaio de flexão sob três pontos (F3P). 


\subsubsection{Ensaio de queda de peso}

Os ensaios de impacto foram conduzidos em um sistema de pequeno porte, construído artesanalmente e esquematizado na Figura 6. A coleta de dados foi realizada utilizando-se concomitantemente um velocímetro Laser-Doppler e uma célula de carga piezelétrica digital com fundo de escala de $500 \mathrm{~N}$. Os espécimes ensaiados foram engastados e travados perimetralmente em uma moldura de aço fixada firmemente ao dispositivo de queda de peso, deixando-se um vão com dimensões no plano de $\left(17,5\right.$ x 40) $\mathrm{mm}^{2}$ para que o laminado defletisse livremente durante o impacto único central. O travamento do espécime garante uma condição de maior restrição à sua deformação (stiffening), favorecendo, portanto, o desenvolvimento dos mecanismos de fratura no LMF. Desta forma, resultados conservadores de energia absorvida, se comparados aos da condição sem travamento, foram provavelmente obtidos no presente estudo.

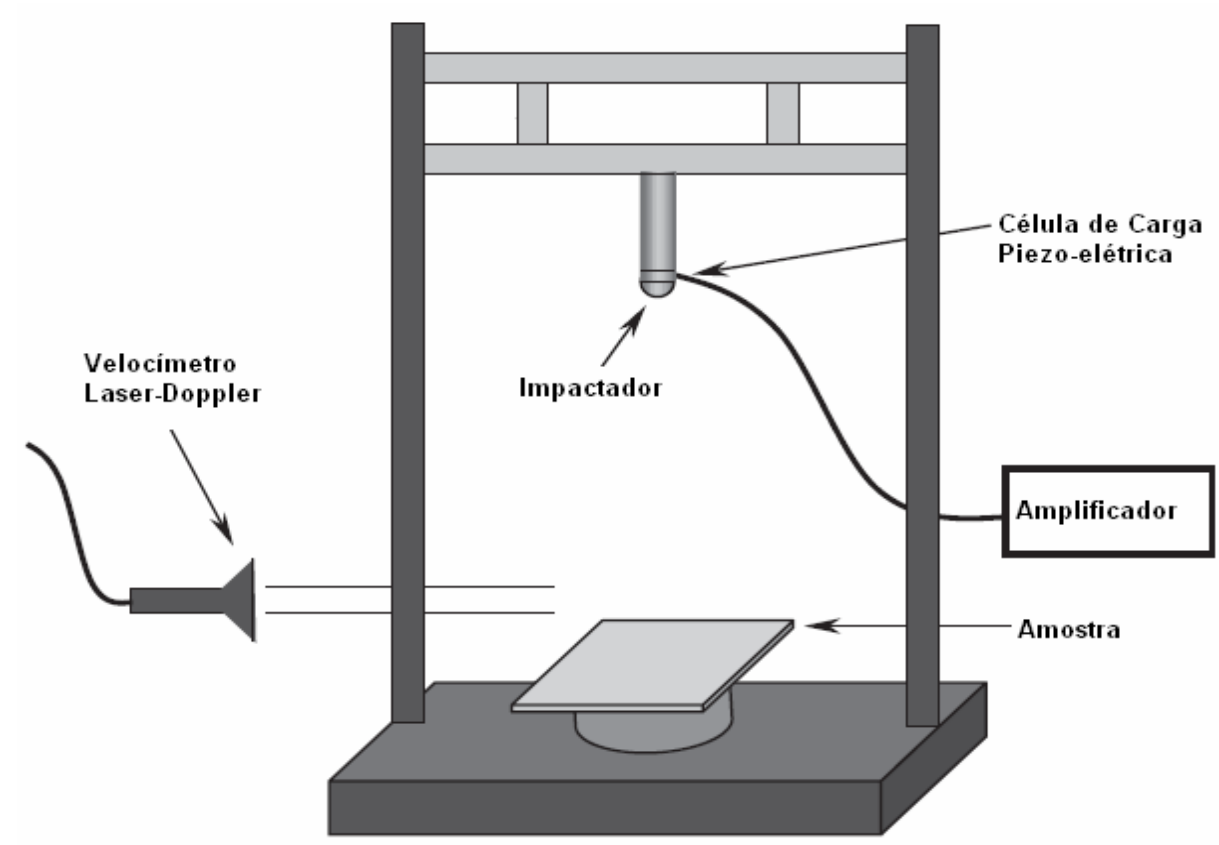

Figura 6: Esquemático do dispositivo de ensaio de impacto por queda de peso [10].

Impactadores de ponta esférica com $5 \mathrm{~mm}$ de diâmetro e massas de, respectivamente, 0,102 kg e 0,530 kg foram empregados. Mitrevski [24] demonstrou que, para uma mesma energia de impacto, ponteiras arredondadas causam uma área mais extensa de danos internos em laminados compósitos, os quais, por sua vez, comprometem mais severamente as propriedades residuais desta classe de matérias (i.e., geram resultados mais conservadores).

Tabela 1: Energia de impacto e a correspondente massa do impactador.

\begin{tabular}{l|l}
\hline Energia de impacto, Joules & Massa do impactador, $\boldsymbol{k g}$ \\
\hline 0,96 & 0,103 \\
\hline 1,90 & 0,530 \\
\hline 2,66 & 0,530 \\
\hline 4,10 & 0,530 \\
\hline 5,00 & 0,530 \\
\hline 6,00 & 0,530 \\
\hline
\end{tabular}


A condução dos experimentos LD e CC seguiu, respectivamente, as etapas estabelecidas no fluxograma da Figura 7, enquanto o método MR é sucintamente descrito no fluxograma da Figura 8.

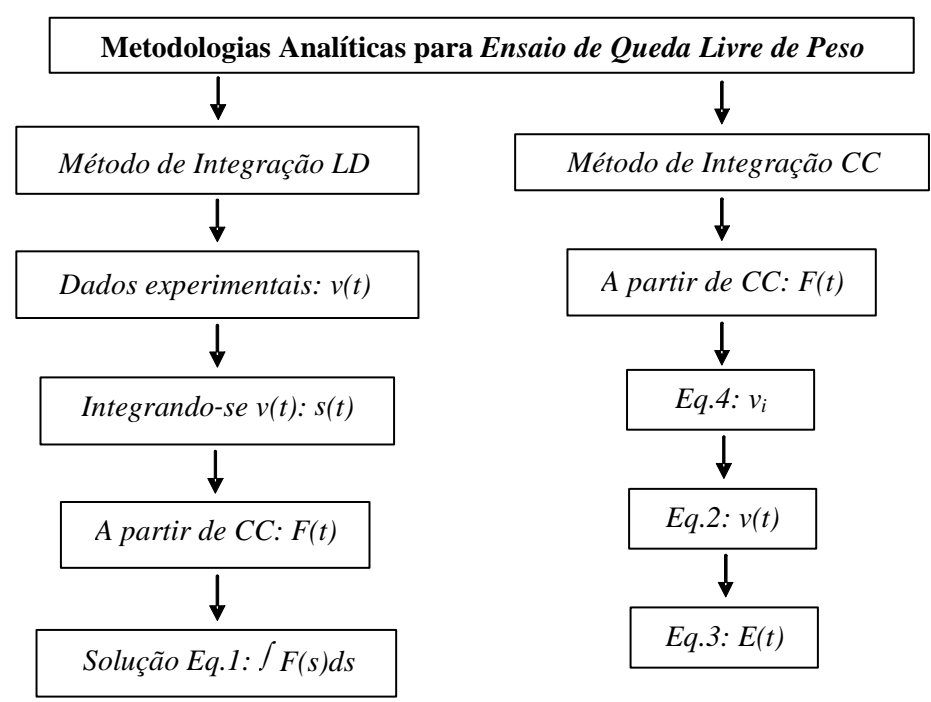

Figura 7: Fluxograma detalhado dos métodos LD e CC.

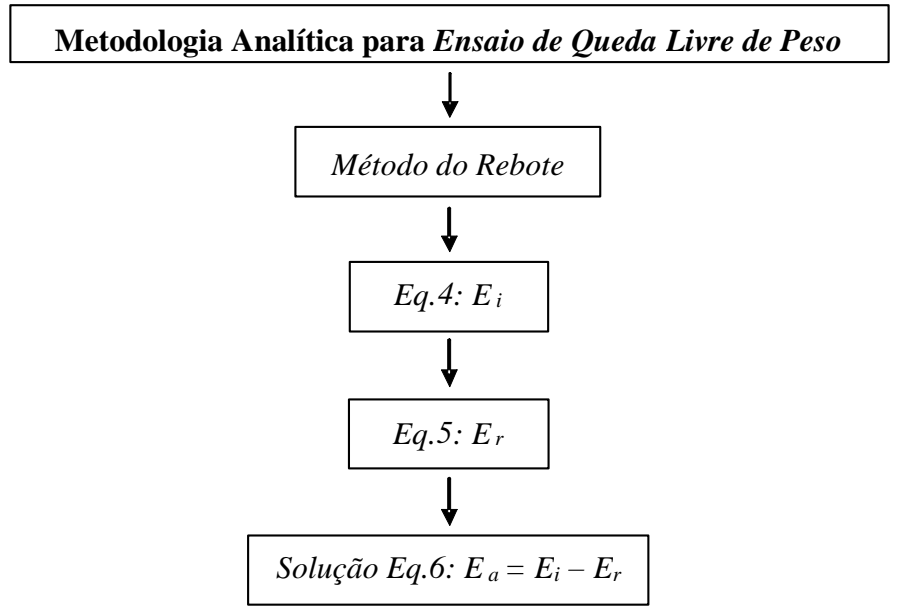

Figura 8: Fluxograma detalhado do método MR.

\subsubsection{Ensaio de flexão sob três pontos (F3P)}

Os ensaios F3P foram realizados em um sistema eletro-mecânico da EMIC ${ }^{\circledR}$ com fundo de escala de 1 ton., sob uma velocidade de deslocamento do travessão de $1 \mathrm{~mm} / \mathrm{min}$. A distância entre os pontos de apoio laterais foi mantida em $40 \mathrm{~mm}$, empregando-se pinos de suporte lateral e de flexão central com $8 \mathrm{~mm}$ de diâmetro. A utilização de um extensômetro axial, localizado exatamente na linha de aplicação da carga lenta e monotonicamente imposta aos tabletes em flexão, possibilitou a obtenção de diagramas de carga vs. deslocamento, ou deflexão na linha de carga (exemplificado na Figura 9). 


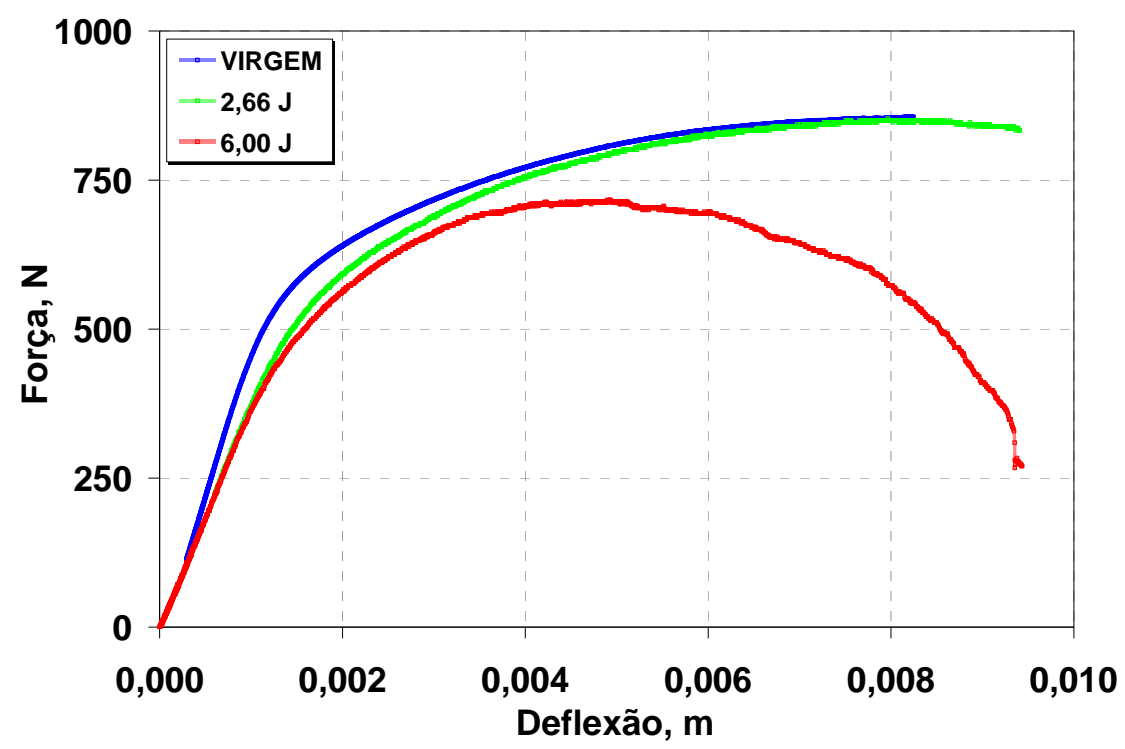

Figura 9: Exemplos de diagramas de carga vs. deflexão na linha de carga para o LMF Glare-5 nas condições de virgem e impactado em dois distintos níveis de energia.

Estes diagramas foram posteriormente convertidos em gráficos de tensão vs. deformação, sendo ambas as quantidades (tensão e deformação) calculadas na posição de máximo esforço trativo dos espécimes, que se localiza na superfície externa do LMF, oposta àquela de contato com o pino central de aplicação da carga fletiva. Fórmulas matemáticas são providas pela norma ASTM-D7264 [25] para a determinação destas quantidades a partir de ensaios de flexão de laminados compósitos.

Os gráficos de tensão vs. deformação em flexão possibilitaram a determinação das seguintes propriedades mecânicas dos tabletes previamente impactados: resistência máxima, módulo de elasticidade e tenacidade de carga máxima. Os dois primeiros parâmetros foram determinados rigorosamente de acordo com as diretrizes estabelecidas em [25]. Neste sentido, o módulo de elasticidade foi obtido como a razão entre o intervalo de tensão e o correspondente intervalo de deformação numa faixa de deformações de 0,1 a 0,3\%. Já a tenacidade de carga máxima foi obtida pela integração da curva de tensão vs. deformação até o ponto de máxima resistência do espécime.

\section{4}

RESULTADOS E DISCUSSÃO

\subsection{Laser-Doppler (LD)}

A Figura 10 apresenta os diagramas de força $(F)$ de impacto em função do deslocamento do impactador (s) obtidos segundo o método LD.

A integração numérica da área sob as curvas $F$-s possibilita a estimativa da energia absorvida $\left(\mathrm{E}_{a}\right)$ pelos espécimes LMF durante a ação de choque mecânico pelo impactador de ponta esférica. Os valores de $E_{a}$ e da energia disponibilizada no momento do impacto $\left(E_{t}\right)$ são apresentados na Figura 11. Conclui-se que o percentual de energia absorvida pelos cdps (i.e., razão $\mathrm{E}_{a} / \mathrm{E}_{t}$ ) oscila entre $70-80 \%$ da energia aplicada no impacto. 


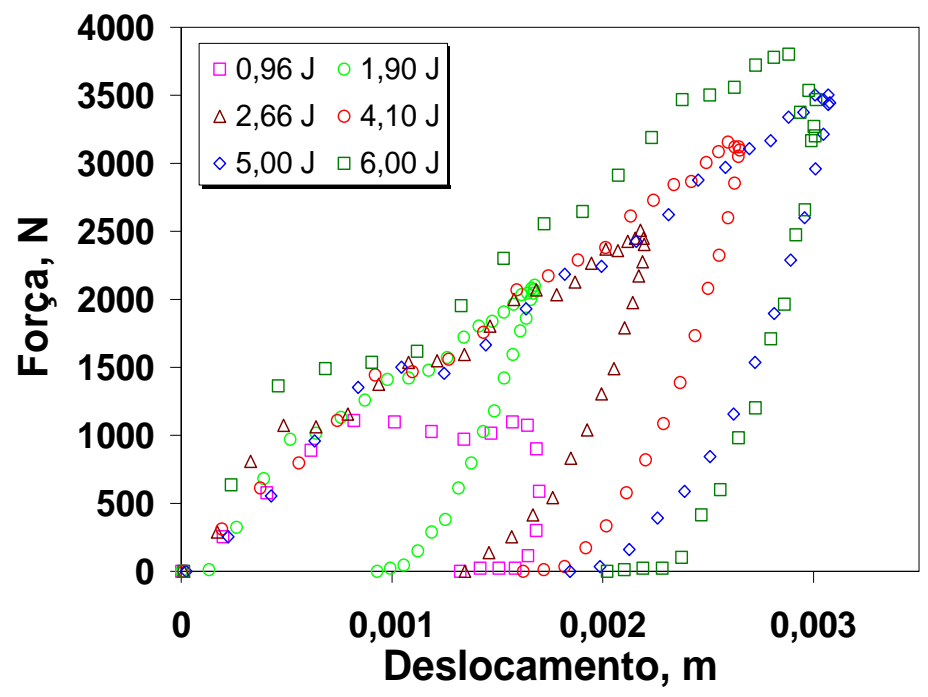

Figura 10: Diagramas de carga em função do deslocamento para diversas energias de impacto do LMF Glare-5.

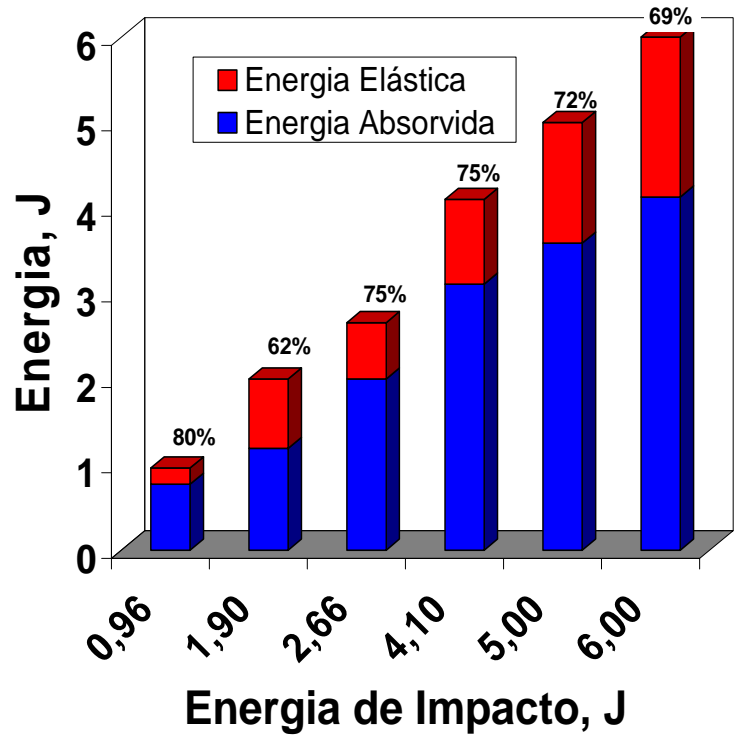

Figura 11: Energia de impacto $\left(\mathrm{E}_{t}\right)$ e correspondentes parcelas complementares de energias absorvida (consumida, $\mathrm{E}_{a}$ ) e recuperada (elástica, $\mathrm{E}_{r}$ ), estimadas segundo o método LD. Note-se que $\mathrm{E}_{t}=\mathrm{E}_{a}+\mathrm{E}_{r}$. $\mathrm{A}$ energia absorvida é também fornecida numericamente, em termos percentuais, relativamente à energia total impressa ao espécime pelo impactador $\left(\mathrm{E}_{a} / \mathrm{E}_{t} * 100 \%\right)$.

\subsection{Célula de carga (CC)}

A Figura 12 mostra um típico gráfico de energia em função do tempo de impacto, obtido por intermédio da Eq. 3. Conforme anteriormente mencionado, as parcelas de energias absorvida $\left(E_{a}\right)$ e recuperada $\left(E_{r}\right)$ compõem essencialmente a energia total $\left(E_{t}=E_{a}+E_{r}\right)$ disponibilizada pelo impactador no momento do choque mecânico transversal contra o alvo de Glare-5.

Na Figura 13 são plotados os valores de $E_{a}$ e $E_{r}$ tal como estimados pela metodologia CC. Verificase que a razão $E_{a} / E_{t}$, neste caso, oscila entre $60-75 \%$ da energia aplicada no impacto, denunciando assim o caráter conservador do método CC frente ao LD (item 4.1). 


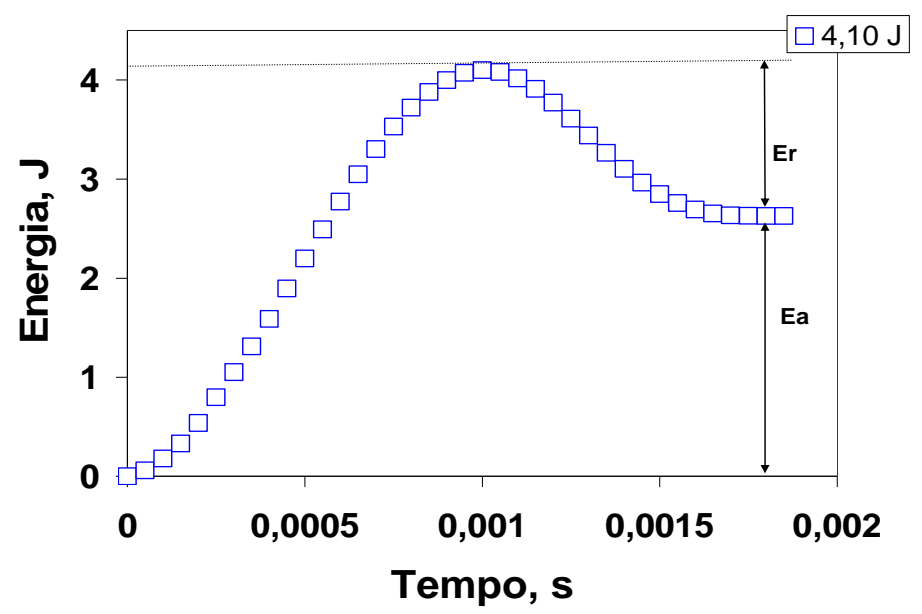

Figura 12: Gráfico de evolução no tempo das energias absorvida $\left(\mathrm{E}_{a}\right)$ e restituída ou recuperada ( $\left.\mathrm{E}_{r}\right)$, obtido em experimento de impacto a 4,10 Joules via método CC.

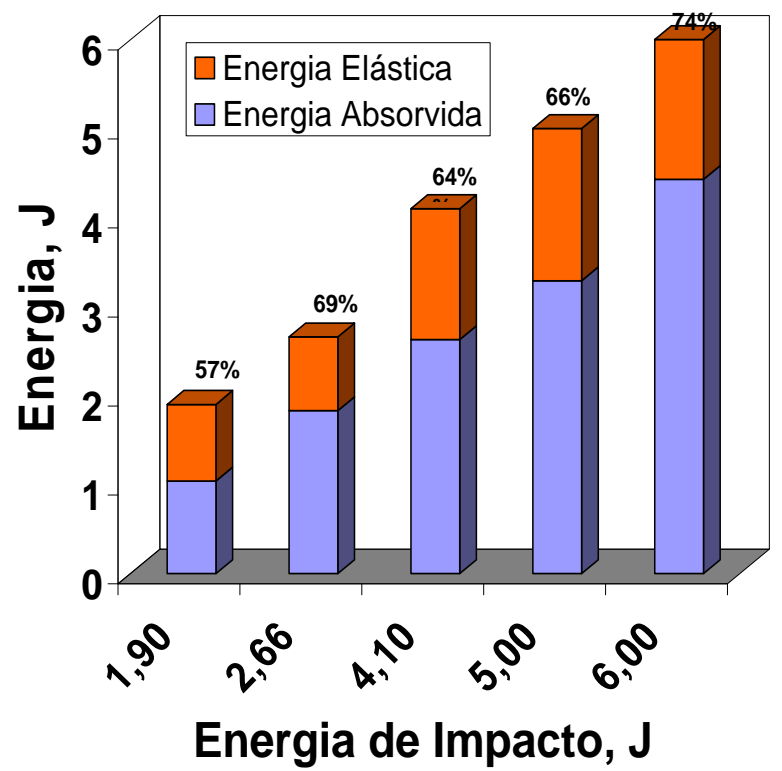

Figura 13: Energia $E_{t}$ e parcelas de energia $E_{a}$ e $E_{r}$ estimadas segundo o método CC. A relação $E_{a} / E_{t}$ é também fornecida numericamente, em termos percentuais.

Na Figura 14 são confrontadas as estimativas de energia absorvida pelo Glare-5 nos ensaios realizados segundo, respectivamente, os métodos LD (item 4.1) e CC (4.2). Verifica-se que o primeiro método tende a produzir resultados superiores àqueles determinados por intermédio do método concorrente, por quase toda a ampla faixa de energias de impacto amostrada no presente estudo.

Em princípio, esta superestimativa do método LD perante o CC decorre do deslocamento lateral, por menor que ele seja, experimentado pelo impactador durante o seu estágio de rebote, ocasião em que o projétil sofre uma reaceleração ao se afastar do alvo fixo de LMF após se chocar contra o mesmo. A rigor, a trajetória pós-impacto do projétil deveria coincidir exatamente, porém obviamente em sentido inverso, com a sua trajetória pré-impacto, a qual é, idealmente, perfeitamente normal à face do laminado Glare-5. Estes pequenos deslocamentos laterais, imperceptíveis ao olho humano, porém perfeitamente detectados pelo sistema Laser-Doppler, podem ser promovidos por fatores que vão desde mínimos desalinhamentos do laminado engastado na moldura de aço, a leves imperfeições no raio de curvatura da ponta do impactador, até sutis variações de propriedades mecânicas superficiais do LMF. Os deslocamentos laterais do impactador no estágio de rebote são interpretados de modo errôneo pelo sistema LD, que infere uma velocidade mais lenta daquela com que realmente o projétil se afasta do alvo, haja vista que o Laser-Doppler só mensura deslocamentos verticais, ou seja, paralelos à direção de ataque do impactador durante sua queda livre contra o LMF. Desta forma, uma subestimativa, por parte do sistema LD, da verdadeira reaceleração adquirida pelo 
impactador imediatamente após o impacto significa, em outros termos, uma superestimativa da energia absorvida pelo espécime durante o evento de choque mecânico.

A Figura 14 confronta os resultados de Ea obtidos, respectivamente, pelos métodos LD e CC. Uma linha tracejada com inclinação de $45^{\circ}$ permite rapidamente identificar quaisquer desvios entre os valores calculados pelas duas abordagens concorrentes. O gráfico indica que o erro de leitura do sistema LD quanto à real velocidade de rebote do impactador, levando a valores superestimados de Ea com relação ao método CC, ocorre para níveis de energia de impacto de até 4 Joules, quando as deformações geradas na superfície do laminado, na forma de uma calota hemisférica impressa, são relativamente pequenas. A partir desta energia, a Figura 14 indica a ocorrência de uma inversão de comportamento, de modo a que o método CC passa, aparentemente, a adquirir um caráter não-conservador quanto à estimativa da energia absorvida pelo LMF Glare no evento do impacto. Tal fato deve provavelmente estar diretamente vinculado à relativamente elevada energia do impacto aplicado (acima de 4 Joules) e à conseqüente maior dimensão da calota formada na superfície metálica do LMF. Nestas condições, pode-se postular que os efeitos acima citados, de desalinhamento do laminado, imperfeições na curvatura do impactador, e variâncias de propriedades do LMF, as quais possivelmente causem deslocamentos do impactador após o choque contra o alvo, sejam minimizados ou até mesmo eliminados.

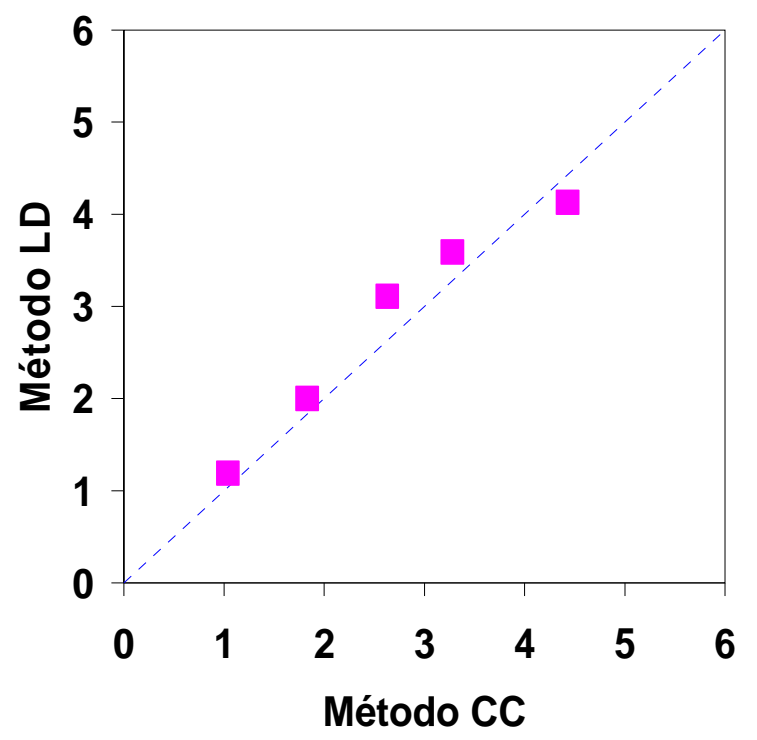

Figura 14: Comparação entre as estimativas da energia $\mathrm{E}_{a}$, em Joules, segundo os métodos LD e CC.

Observa-se que o ponto de dados referente à energia de impacto de $0,96 \mathrm{~J}$ não consta no gráfico, o que decorre de limitações inerentes ao método CC em estimar $\mathrm{E}_{a}$ a partir de ensaios de impacto com energia $\mathrm{E}_{t}$ suficientemente baixa.

\subsection{Rebote (MR)}

Nos cálculos estimativos das energias cinéticas de impacto e de rebote, foram empregados, respectivamente, os valores de velocidade nos limiares de impacto e de retorno do impactador a partir do alvo. Os dados fornecidos pelo sistema LD permitiu calcular estas velocidades e, conseqüentemente, a energia absorvida pelos espécimes ensaiados.

Na Figura 15 são exibidos os resultados de $\mathrm{E}_{a}$ segundo o método do rebote, donde se verifica que a razão $\mathrm{E}_{a} / \mathrm{E}_{t}$ varia no intervalo de 70 a $90 \%$, refletindo a natureza excessivamente liberal, ou nãoconservadora, do método MR frente a ambos os métodos LD e CC. 


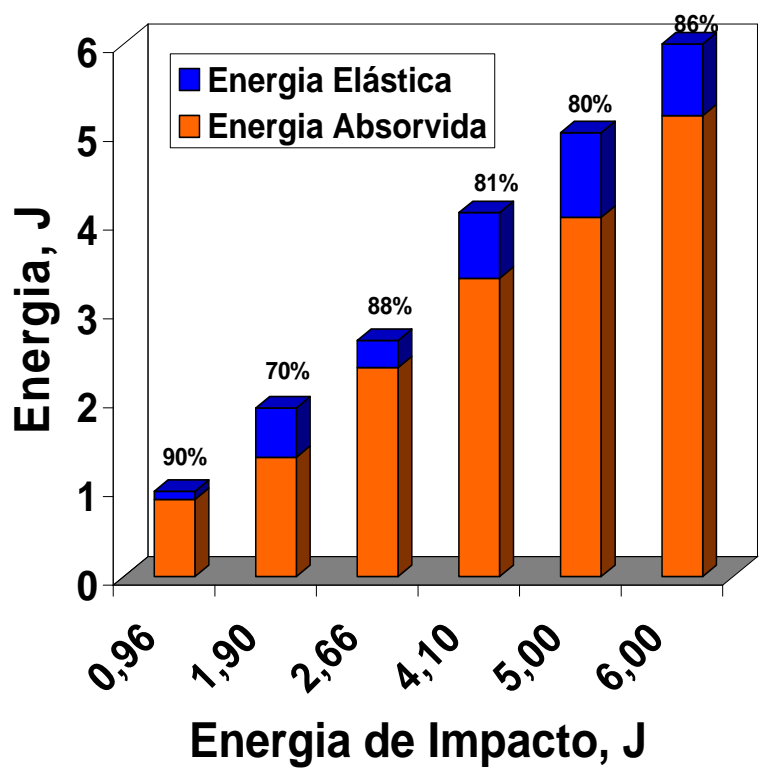

Figura 15: Energia $E_{t}$ e parcelas de energia $E_{a}$ e $E_{r}$ estimadas segundo o método $M R$. A relação $E_{a} / E_{t}$ é também fornecida numericamente, em termos percentuais.

A análise das Figuras 16a e 16b confirma o elevado grau de não-conservadorismo do método MR se comparado, respectivamente, ao LD e ao CC, para toda faixa de energias de impacto amostrada no presente estudo.

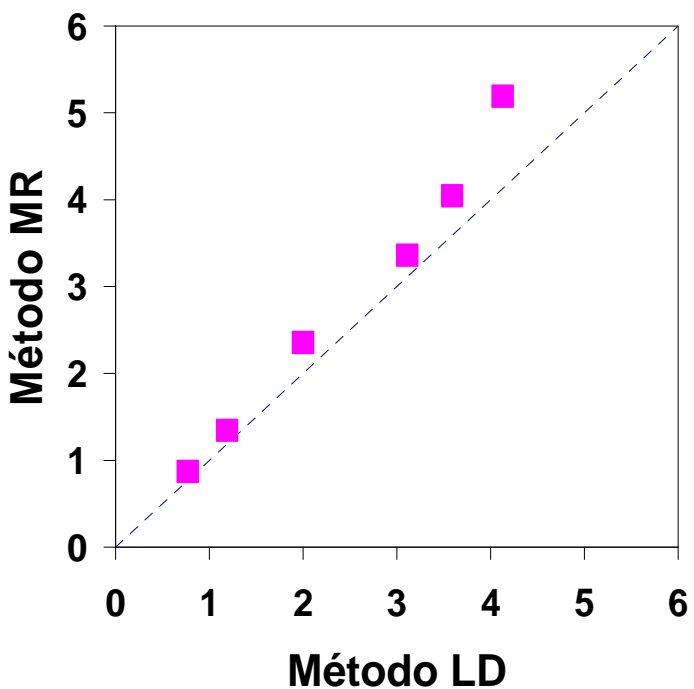

(a)

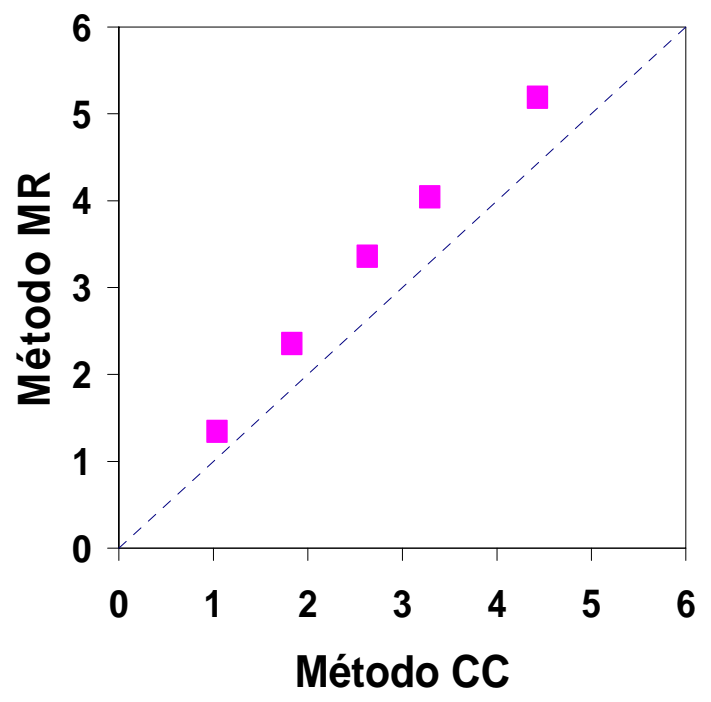

(b)

Figura 16: Comparação entre as estimativas da energia $E_{a}$, em Joules: (a) MR versus LD; (b) MR versus CC. Nota-se na Fig.16b que o ponto de dados referente à energia de impacto de 0,96 J não está plotado, como decorrência de limitações do método $\mathrm{CC}$ em estimar $\mathrm{E}_{a}$ a partir de ensaios de impacto com energia $\mathrm{E}_{t}$ suficientemente baixa.

Em certa proporção, este excessivo liberalismo do método MR advém exatamente do fenômeno acima descrito (item 4.2) de deslocamento lateral do projétil após o choque mecânico, o qual induz valores subestimados da velocidade de rebote do impactador quando esta é mensurada pelo dispositivo LaserDoppler. Uma vez que a energia cinética de rebote, Er (vide Eq.6 referente ao método MR), é calculada por intermédio desta velocidade subestimada provida pelo método LD, o resultado final é também uma subestimativa da componente de energia Er, e, por conseguinte, uma superestimativa da energia Ea do método MR (Eq.6), visto que a parcela complementar de energia Ei é corretamente estimada. 
Entretanto, como a superestimativa do método MR sobre ambos os métodos concorrentes LD e CC (Figura 16) se mantém mesmo para energias de impacto acima de 4 Joules (nível de energia a partir do qual se espera que o método LD não mais produza resultados subestimados de velocidade de rebote, e, conseqüentemente, de energia Er, vide item 4.2) algum outro fator possivelmente esteja atuando no método MR simultânea e sinergicamente ao acima proposto com base no deslocamento lateral pós-impacto do projétil. Este fator adicional muito provavelmente esteja associado ao princípio fundamental do método MR de considerar apenas os dados de entrada e de saída do experimento, ou seja, respectivamente as energias Ei e Er (Eq.6). Em outras palavras, contrariamente ao que fazem os métodos concorrentes LD e CC, o MR não computa a verdadeira história de carregamento do espécime impactado. Desta forma, parte da estimativa superdimensionada dos valores de energia absorvida pelo Glare-5 provavelmente resulte do cômputo de uma parcela extra de energia, que não somente aquela demandada por mecanismos de fratura e de deformação permanente do laminado híbrido, quais sejam: delaminações, quebra de fibras, trincamento da matriz polimérica, deformação plástica da fase metálica e viscosa do polímero, dentre outros. Por exemplo, pode-se hipotetizar que a energia devida à fricção entre o impactador e o LMF, assim como entre o laminado e a moldura em que o mesmo é engastado, além daquela energia associada a deformações elásticas do laminado, em ambos os níveis local (endentação) e global (de todo material circundado pela moldura de aço), seja equivocadamente interpretada pelo método MR como sendo absorvida ou consumida pelo Glare-5 sob impacto transversal.

\subsection{Resistência mecânica residual}

A resistência residual em flexão do LMF Glare-5, após impacto único centralizado transversal de baixa velocidade com energia entre 0,96 e 6,00 Joules, é fornecida nas Figuras 17-20. Como linha-de-base são fornecidos os resultados obtidos para o material no estado virgem, ou como-recebido.

Observa-se que a resistência máxima residual em flexão do Glare (Figura 17) apresenta um comportamento anômalo para energias de impacto de até 5,00 J, indicando a possibilidade de o material ter sido eventualmente reforçado, ou fortalecido pelo impacto previamente aplicado. Este comportamento é corroborado pela análise da Figura 18, que fornece as curvas de tensão vs. deformação para o LMF-Glare em todas as condições em que o material foi avaliado.

Este aumento da resistência residual do Glare, relativamente à condição virgem do material, constitui uma resposta contrária à esperada do LMF, já que a sua integridade estrutural comprovadamente degradada devido ao impacto, o qual tipicamente gera delaminações, quebra de fibras e trincas na matriz polimérica dos laminados compósitos, e, portanto, seu enfraquecimento.

Especula-se que os resultados de flexão residual após o impacto tenham sido afetados, em maior ou menor extensão, pela geração da calota hemisférica no LMF durante o choque mecânico (Figura 21), a qual alterou significativamente a geometria local do cdp. Pode-se, portanto, argüir que o módulo da seção [26] do laminado (um parâmetro eminentemente geométrico) tenha sido incrementado a ponto de mais do que compensar o decréscimo da resistência à flexão devido aos danos introduzidos no Glare, resultando num aumento da resistência mecânica efetiva do cdp. Segundo as Figuras 17 e 18, somente para uma energia de impacto de 6,00 J o comportamento esperado de perda de resistência do laminado foi restabelecido. Nestas circunstâncias, o balanço entre o comportamento essencialmente material, governado pela integridade estrutural do laminado, e o comportamento intrinsecamente mecânico, ditado pela geometria do cdp, pende para o primeiro termo da equação.

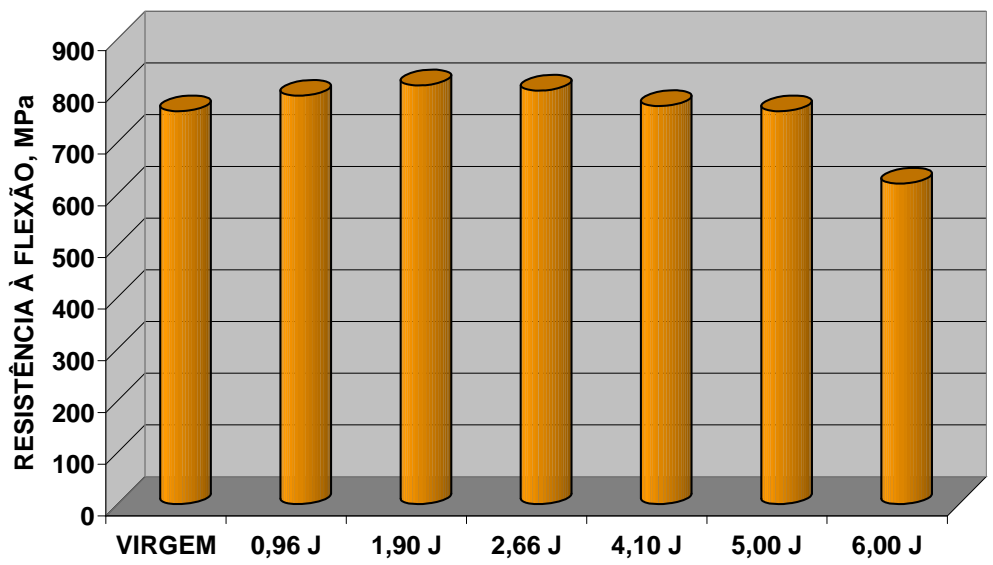

Figura 17: Comparação entre o desempenho do laminado metal/fibra Glare no quesito de resistência máxima à flexão, após impacto único sob vários níveis de energia. A resistência do material na condição virgem é plotada para fins de comparação. 


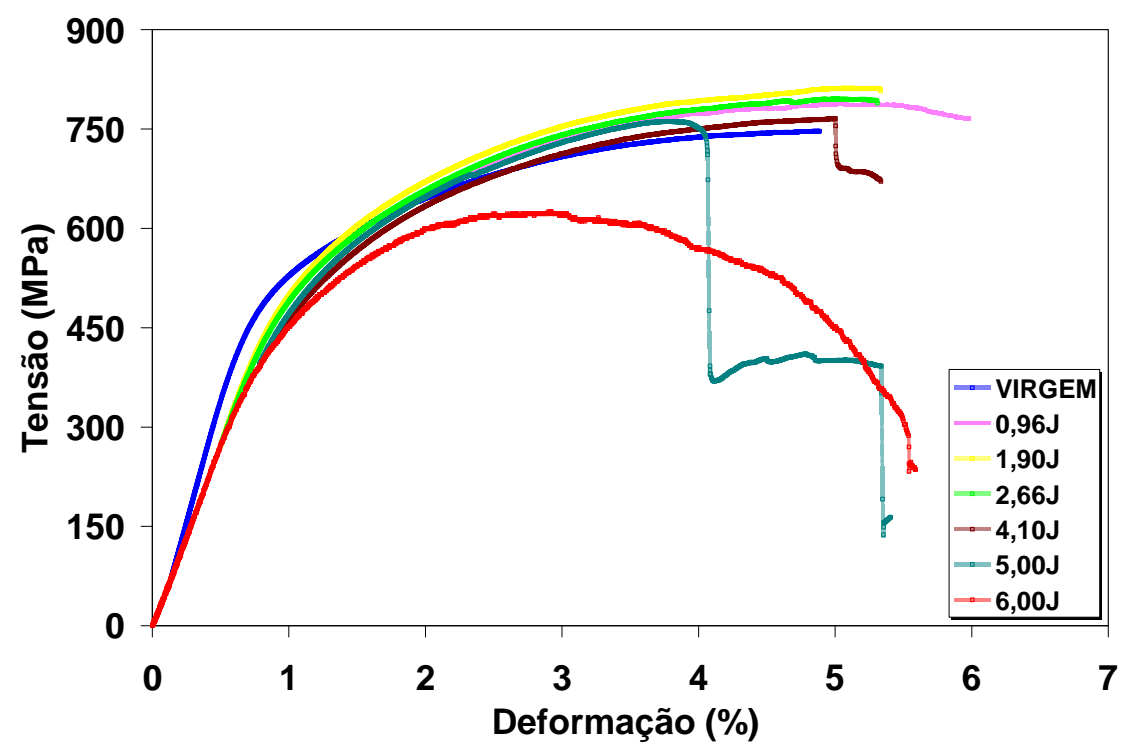

Figura 18: Curvas de tensão vs. deformação em flexão do LMF Glare-5 nas condições de virgem e impactado em seis distintos níveis de energia.

Nota-se, por outro lado, que o módulo de elasticidade, ou a rigidez sob flexão do material (Figura 19), é uma propriedade mecânica residual que reage do modo muito consistente relativamente aos diferentes níveis de energia de impacto previamente aplicado ao laminado híbrido Glare-5. De fato, e como esperado com base na perda da integridade do material devido aos danos crescentes criados previamente por impacto, esta propriedade apresenta uma tendência muito clara e bem definida de decréscimo na medida em que a energia do choque mecânico é incrementada. Conclui-se daí que um provável aumento do módulo da seção do cdp devido ao impacto foi mais que compensado pela degradação sofrida pelo Glare no choque mecânico, de sorte que a rigidez do LMF foi determinada por este último termo para todas as energias de impacto aplicadas no material híbrido.

Interessante observar que a tenacidade residual de carga máxima em flexão (Figura 20) também se constitui, embora de um modo não tão evidente quanto o módulo de Young do material, num parâmetro sensível, e de modo consistente, aos danos previamente introduzidos por impacto ao laminado Glare-5.

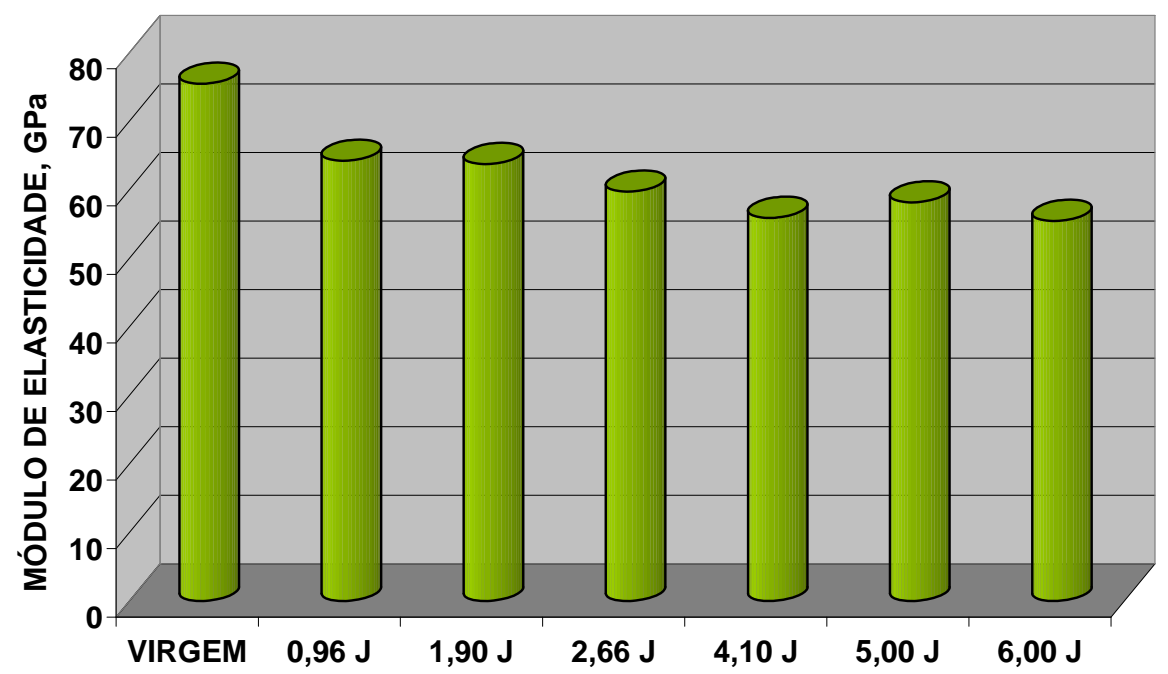

Figura 19: Desempenho do laminado metal/fibra Glare no quesito de módulo de elasticidade, após impacto único sob vários níveis de energia. A resistência do material na condição virgem é plotada para fins de comparação. 


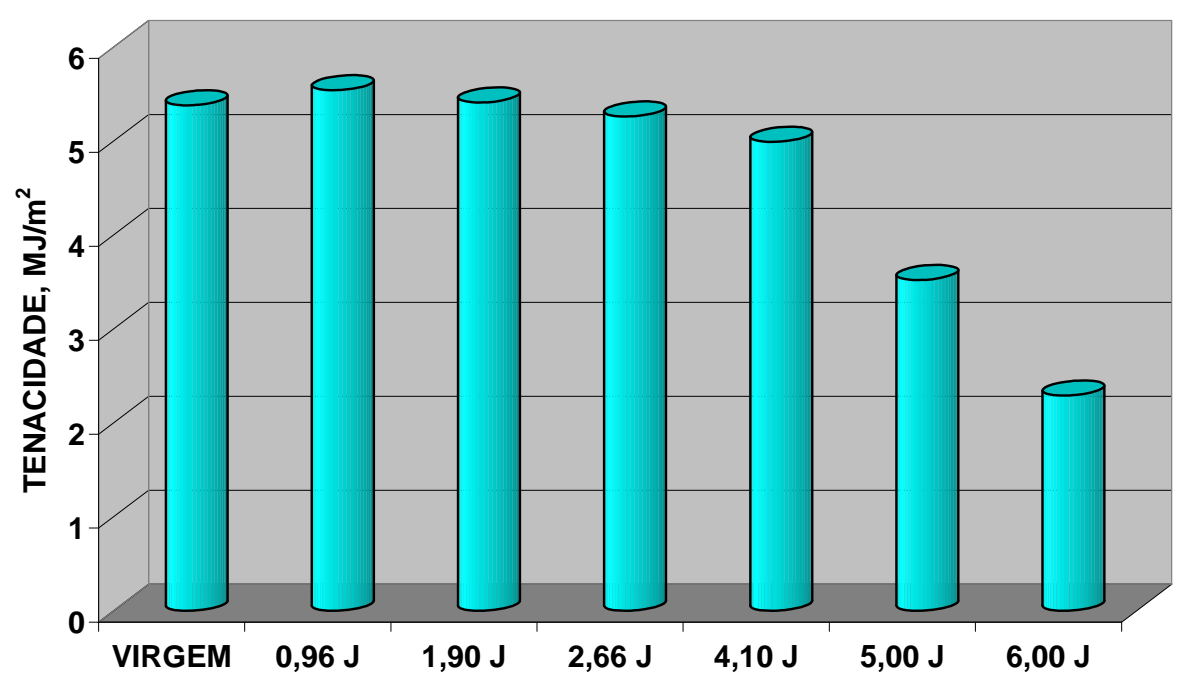

Figura 20: Comparação entre o desempenho do laminado metal/fibra Glare no quesito de energia absorvida (i.e., tenacidade) até a carga máxima em flexão, após impacto único sob vários níveis de energia. A tenacidade do material na condição virgem é plotada para fins de comparação.

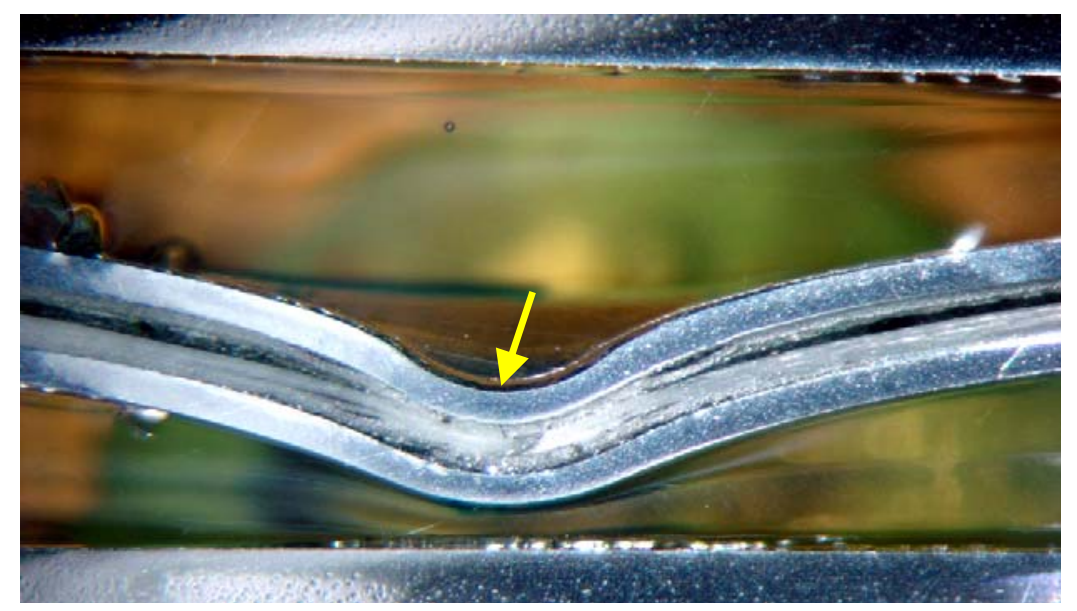

Figura 21: Vista geral em corte metalograficamente polido da seção longitudinal de um espécime de Glare-5 impactado pelo projétil de ponta esférica de aço (diâmetro de $5 \mathrm{~mm}$ ) com uma energia incidente de 6,00 Joules. Observam-se claramente as calotas formadas nas faces frontal (indicada por seta amarela) e posterior do cdp.

Na Figura 22 são observadas vistas ampliadas da seção longitudinal do cdp anteriormente mostrado na Figura 21. Confirma-se a massiva presença de delaminações, tanto na região central de impacto (Fig.22a, particularmente na interface entre o compósito fibra/resina e a lâmina metálica posterior- $P$ ), quanto em posições mais remotas do espécime (Figs 22b e 22c, desta feita na interface do compósito com a lâmina metálica frontal- $F$ ), sempre acompanhadas por processos de separação, maceração e rompimento das fibras cerâmicas de reforço. 


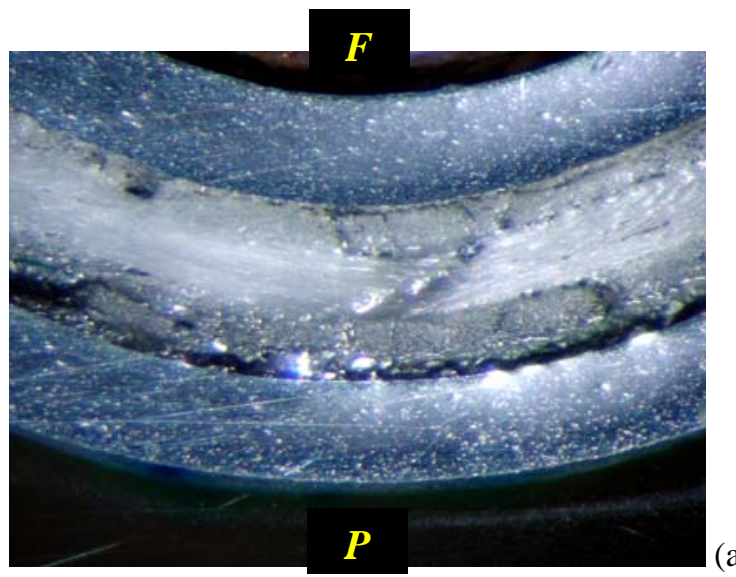

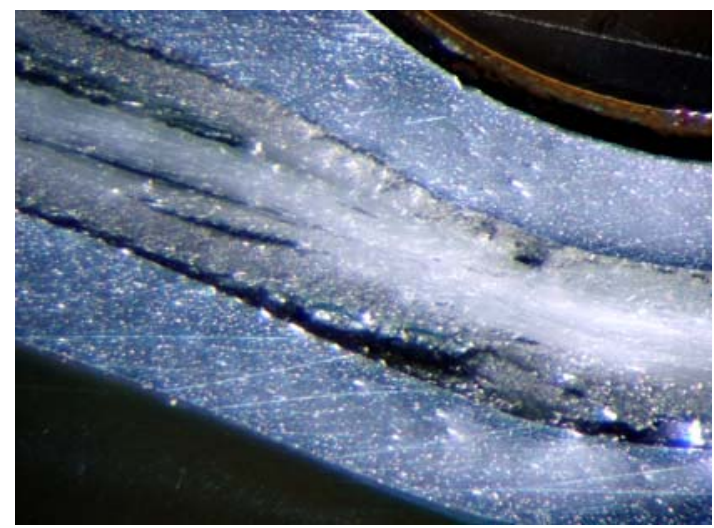

(b)

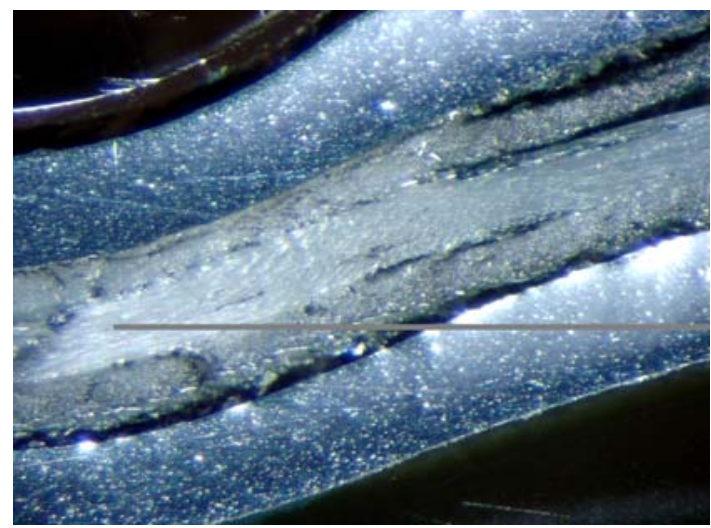

(c)

Figura 22: Vistas locais em corte metalograficamente polido da seção longitudinal na região de impacto do laminado Glare-5 mostrado anteriormente na Figura 21.

Os resultados obtidos no presente trabalho permitem concluir que:

1. De acordo com os métodos LD e CC, o Glare-5 absorve entre $60 \%$ e $80 \%$ da energia aplicada sob impacto classificado como leve, até 6,00 Joules;

2. Os métodos LD e CC produzem resultados satisfatoriamente próximos de energia absorvida no impacto, com diferenças oscilando entre 7 e 20\%. Porém, o método LD tende a ser nãoconservador frente ao CC, e este caráter mais liberal advém dos deslocamentos laterais sofridos pelo projétil após atingir o ponto de máxima penetração no alvo, os quais não são devidamente computados pelo sistema de monitoração por Laser-Doppler;

3. Ficou, portanto, claramente evidenciada a viabilidade da determinação da resistência a danos por impactos leves de laminados metal/fibra através de um experimento simples e rápido (CC), que utiliza apenas uma célula de carga digital para a monitoração da força aplicada em função do tempo, superando possíveis limitações quanto à disponibilidade de equipamentos laboratoriais mais sofisticados (LD) na indústria da mobilidade;

4. O módulo de elasticidade residual e a tenacidade residual de carga máxima em flexão são propriedades substancialmente sensíveis à presença de danos previamente introduzidos por impacto no LMF Glare-5, refletindo de modo consistente e inequívoco as esperadas perdas de propriedades mecânicas decorrentes do choque mecânico prévio do material;

5. Ficou, portanto, também claramente evidenciada a viabilidade da determinação da tolerância a danos por impactos leves de laminados metal/fibra através de um experimento laboratorial simples e rápido (F3P), que utiliza apenas um sistema universal de ensaios mecânicos instrumentado com uma célula de carga e um extensômetro digitais para a determinação de curvas carga vs. deslocamento na linha de carga, facilmente disponíveis em toda a indústria da mobilidade. 
À Aviation Equipments (CA-USA) pelo suprimento do LMF-Glare-5, à Embraer S/A pela usinagem e preparo dos cdps, ao Prof. W.J. Cantwell da Universidade de Liverpool (UK) por prover todas as facilidades para os ensaios de impacto, e aos Profs. D. Spinelli e W.W. Bose da Escola de Engenharia de São Carlos por disponibilizarem os equipamentos para os ensaios de resistência mecânica residual.

\section{REFERÊNCIAS}

[1] VOGELESANG, L.B., VLOT, A., "Development of fiber-metal laminates for advanced aerospace structures”, Journal Materials Processing \& Technology, v.103, n.1, p.1-5, Jun. 2000.

[2] BEUMLER, T., STAIKOV, R., GENNAI, A., SENATOROVA, O., "Controlling the damage with fibermetal laminate structures", In: Proceedings of the $1^{\text {st }}$ International Conference on Damage Tolerance of Aircraft Structures, TU Delft, The Netherlands, Paper 32, Sep. 2007.

[3] MOSSE, L., COMPSTON, P., CANTWELL, W.J., CARDEW-HALL, M., KALYANASUNDARAM, S., "The effect of process temperature on the formability of polypropylene based fibre-metal laminates", Composites: Part A, v.36, n.8, p.1158-1166, Aug. 2005.

[4] MOSSE, L., COMPSTON, P., CANTWELL, W.J., CARDEW-HALL, M., KALYANASUNDARAM, S., "Stamp forming of polypropylene based fibre-metal laminates: the effect of process variables on formability”, Journal of Materials Processing Technology, v.172, n.2, p.163-168, Feb. 2006.

[5] KANG, H., "Fatigue prediction of lightweight thermoplastic fiber-metal laminates", Journal of Testing and Evaluation, v.35, n.3, p.266-271, May 2007.

[6] SUN, C.T., DICKEN, A., WU, H.F., "Characterization of impact damage in Arall laminates”, Composite Science \& Technology, v.49, n.2, p.139-144, Jun. 1993.

[7] VLOT, A., "Impact loading on fiber metal laminates", International Journal of Impact Engineering, v.18, n.3, p.291-307, Apr.1996.

[8] VLOT, A., KROON, E., LA ROCCA, G., "Impact response of fiber metal laminates”, in Kim, J.K, Yu, T.X. Ed., Impact Response and Dynamic Failure of Composites and Laminate Materials - Key Engineering Materials, v.141-143, n.1, p.235-276, Trans Tech Publ., Switzerland, 1998.

[9] HOO FATT, M.S., LIN, C., REVILOCK, Jr. D.M., HOPKINS, D.A., "Ballistic impact of Glare fibermetal laminates”, Composite Structures, v.61, n.1-2, p.73-88, Jul. 2003.

[10]CORTÉS, P., CANTWELL, W.J., "The impact properties of high-temperature fiber-metal laminates", Journal of Composite Materials, v. 41, n.5, p.613-632, Mar. 2007.

[11]ATAS, C., "An experimental investigation on the impact response of fiberglass/aluminum composites", Journal of Reinforced Plastics \& Composites, v.26, n.14, p.1479-1491, Sep. 2007.

[12]BERNHARDT, S., RAMULU, M., KOBAYASHI, A.S., "Low-velocity impact response characterization of a hybrid titanium composite laminate", ASME Journal of Engineering Materials \& Technology, v.129, n.2, p.220-226, Apr. 2007.

[13] GWEON, S.Y., BASCOM, W.D., "Damage in carbon-fibre composites due to repetitive low-velocity impact loads”, Journal of Materials Science, v.27, n.8, p.2035-2047, Apr. 1992.

[14] MITTELMAN, A., "Low-energy repetitive impact in carbon-epoxy composite”, Journal of Materials Science, v.27, n.9, p.2458-2462, May 1992.

[15] KHAN, B., RAO, R.M.V.G.K., VENKATARAMAN, N., "Low velocity impact fatigue studies on glass epoxy composite laminates with varied material and test parameters - effect of incident energy and fibre volume fraction”, Journal of Reinforced Plastics \& Composites, v.14, p.1150-1159, 1995. 
[16]LANNING, D.B., "The residual fatigue strength of 2024-T4 with foreign object damage”, In: Proceedings of the $9^{\text {th }}$ International Fatigue Congress, Atlanta-GA, USA, May 2006. Abstract Ref. FT380, 2006.

[17]TARPANI, J.R., ANGELONI, M., IEZZI, L., CASTRO, C.E.G., "Fadiga após múltiplos impactos em laminados carbono-epóxi”, Tecnologia em Metalurgia e Materiais, v.2, n.4, p.63-70, Abril-Junho 2006.

[18]DE FREITAS, M., REIS, L., "Failure mechanisms on composite specimens subjected to compression after impact”, Composite Structures, v.42, n.4, p.365-373, Aug. 1998.

[19] HONG, S., LIU, D., “On the relationship between impact energy and delamination area”, Experimental Mechanics, v.29, n.2, p.115-120, Jun. 1989.

[20] ALDERLIESTEN, R.C., HOMAN, J.J., "Fatigue and damage tolerance issues of Glare in aircraft structures”, International Journal of Fatigue, v.28, n.10, p.1116-1123, Oct. 2006.

[21]HOSSEINZADEH, R., SHORKRIEH, M.M., LESSARD, R., "Damage behavior of fiber reinforced composite plates subjected to drop weight impacts", Composite Science \& Technology, v.66, n.1, p.6168, Jan. 2006.

[22]KALTHOFF, J.F., "Characterization of the dynamic failure behaviour of a glass-fiber/vinyl-ester at different temperatures by means of instrumented Charpy impact testing”, Composites: Part B: Engineering, v.35, n.6-8, p.657-663, September-December 2004.

[23] MCKOWN, S., CANTWELL, W.J., JONES, N., "Investigation of scaling effects in fiber-metal laminates”, Journal of Composite Materials, v.42, n.9., pp.865-888, 2008.

[24] MITREVSKI, T., MARSHALL, I.H., THOMSON, R., "The influence of impactor shape on the damage to composite laminates”, Composite Structures, v.76, n.1-2, p.116-122, Oct. 2006.

[25] AMERICAN SOCIETY FOR TESTING AND MATERIALS, Designation ASTM-D7264M-07: "Standard test methods for flexural properties of polymer matrix composite materials", ASTM International Handbook, 2007.

[26] GERE, J.M., Mechanics of materials, 7 ed, Toronto, Cengage Learning, 2009. 